\title{
FARMER WANTS A (SWEDISH) WIFE
}

\section{WHITE MOBILITIES IN THE REALITY ROMANCE SHOW BONDE SÖKER FRU - JORDEN RUNT}

\author{
Georgia Aitaki \\ Örebro University \\ georgia.aitaki@oru.se \\ Nina Carlsson \\ Södertörn University \\ nina.carlsson@sh.se
}

\begin{abstract}
In this article we discuss discourses of white mobility in reality television, a genre whose problematic post-racial and neoliberal discourses have long been exposed. Moving beyond the widely researched Anglophone media landscapes, we interrogate the discursive construction of white mobilities in the Swedish romance reality show Bonde Söker Fru - Jorden Runt (TV4, 2019-2020) [Farmer Seeks Wife - Around the World] where Swedish North-to-South migrants working as farmers abroad seek a partner from Sweden through the assistance of reality TV. By focusing on the discursive and visual strategies through which the show perpetuates racial hierarchies, we discuss the colonial imaginaries, the absence of border policies (such as residency, employment, or integration), and the significance of individual migratory preferences in the mobility discourses. We identify three forms of white mobility - the tourist, the adventurer, and the philanthropist - and show that migration is depicted as something reversible, an adventure, and a possibility for self-development, rather than a life-long decision with high stakes.
\end{abstract}

Keywords: Reality TV, race, whiteness, Sweden, borders, Farmer Wants a Wife

\section{Introduction}

This study focuses on the Swedish reality dating show Bonde Söker Fru - Jorden Runt [Farmer Seeks Wife Around the World] (TV4, 2019-2020), where Swedish migrants working as farmers abroad seek a partner from Sweden through the assistance of reality TV. The reality television programme constitutes the Swedish version of the well-known Farmer Seeks Wife franchise under the sub-category of "reality romance shows" which follow "the development of a romantic relationship over time in a serial format." It premiered on Swedish television in 2008 and has run for 14 seasons. The 'Around the World' spin-off constitutes a twist of the original idea with the farmers being based outside Sweden, yet looking to marry a Swedish partner (Figure 1). Located at the intersection of critical media and critical whiteness studies, this article aims to provide an ideological analysis of the show, turning the spotlight on the ways that "familiar narrative, visual, or generic structures orient our understanding of what we see and how they naturalize the events and stories on television." 2 Specifically, by focusing on white mobilities, we discuss reality television as a discursive space for the construction of meaning around the pasts and presents of North-South migration. 
The study analyses nine episodes included in the season (one 'casting' episode where the main participants are introduced and eight 'regular' episodes). The 'casting' episode is filmed in the countries of destination (Spain, Australia, Mozambique, and Italy), whereas the speed-dating sessions are filmed in Sweden. Thereafter, a smaller group of women selected by each farmer travel to the countries of destination where they meet the farmers again.

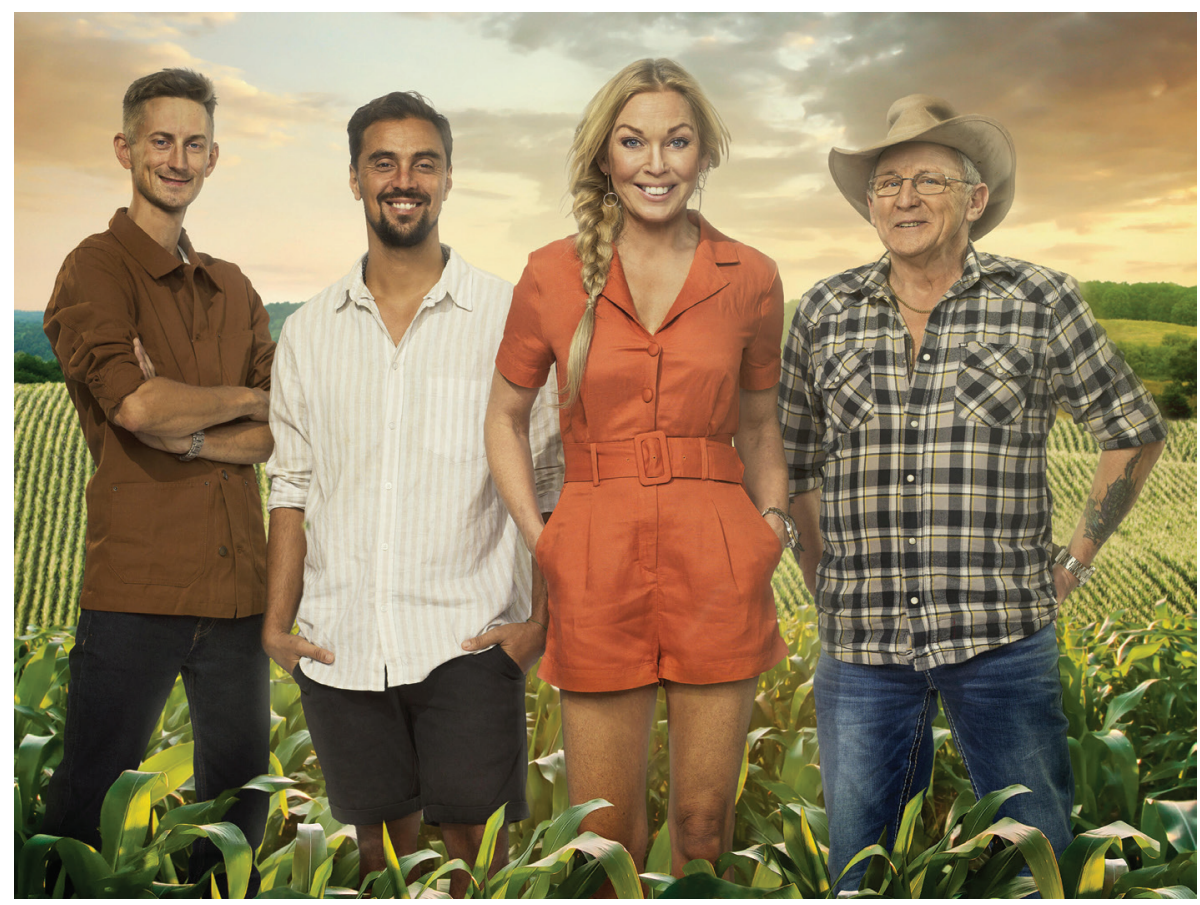

Figure 1. From left to right: Farmers Andreas and Michel, the host Linda Lindorff, and farmer Leif

We propose an understanding of Bonde Söker Fru - Jorden Runt as part of a specific group of reality romance TV shows that focus on mobilities and border-crossings. The fact that Bonde Söker Fru is a romance reality show is not completely negated; Farmer Wants a Wife, a rural edition of the highly successful The Bachelor (the epitome - one could argue - of reality romance TV), utilizes the common tropes of multiple dating on a path for the search of 'the one.' However, this specific edition of Bonde Söker Fru does not exclusively focus on issues of romance and compatibility with the farmer's life, but also on issues of mobility. In this sense, our case in point shares some similarities with reality TV that particularly emphasizes love within the context of travel and cultural difference, such as the popular US show 90 Day Fiancé (2014-present) and its spin-offs 90 Day Fiancé: Before the 90 Days and 90 Day Fiancé: The Other Way, or the Swedish Älskar, Älskar Inte (2021) that depict love migration flows, usually from postcolonial or post-communist nations to the West. In this way, the study aspires to contribute to understandings of how race crosscuts opportunities and barriers to migration and mobility as portrayed in love migration, one of the few forms of mobility taking place within legalized frameworks of migration. Linking whiteness to such mobilities, the study reveals that the programme promotes three colonially charged versions of white mobility, namely the tourist, the adventurer, and the philanthropist. As such, it contributes to the continuous problematization of whiteness as a race discourse in contemporary (reality) television, especially within national (media) contexts that take a colorblind stance on race.

\section{Making Whiteness Strange (Again)}

Drawing from Critical Whiteness Studies which aims at exposing the invisible structures that produce and reproduce white supremacy and privilege, the study of whiteness centralizes the notion of 'invisibility' and, specifically, the study 
of 'white' as a racial category, including the institutionalized strategies that repackage it as the human condition and the norm. ${ }^{3}$ In this sense, making whiteness strange equals a process of "nam[ing] and critiqu[ing] hegemonic beliefs and practices that designate white people as 'normal' and racially 'unmarked."'4 Putting white people under the critical microscope is not then a vengeful step; rather, it is a systematic attempt to understand what whiteness is and what it does through a particular "attention to covert processes that reproduce racial privilege - especially those that do so without appearing to." 5

Studying whiteness is committed to revealing the problems of the invisibility of white identity, namely who benefits and who suffers from whiteness being considered normative and ideal. ${ }^{6}$ This nexus of power relations is encapsulated in the central concept of 'white privilege' defined as a sort of racial advantage including not only a certain immunity in terms of not being restricted by racial realities and oppressive structures, but also a certain kind of freedom in terms of not having to think how these racial realities and structures work in one's favor. Despite its invisibility, whiteness is the result of conscious political processes. As described by Sarah Ahmed, "[t]he institutionalization of whiteness involves work [...]. Institutions involve the accumulation of past decisions about how to allocate resources, as well as 'who' to recruit." Hence, media and media discourses can be seen as institutions involved in producing and reproducing racial hierarchies and relationships of power.

By making whiteness visible as a racial position that deeply forms contemporary media discourses, its invisibility and neutrality is challenged. However, when making whiteness visible and when switching on analytical frameworks employing whiteness as a central concept, it is crucial to do so in a way that is sensitive to context, including race histories and colonial legacies, as well contemporary border regimes and white/transnational capital. ${ }^{8}$ Whiteness is not a question of 'skin colour' or a uniform phenomenon used with the aim of homogenizing complexity. It does not "inhere in bodies," rather it "serves a number of social functions that serve to reinforce a system of domination, not only in relation to race, but sexuality, gender, class, location, and, certainly, nationality." ${ }^{\text {In }}$ this study, we focus on whiteness as deeply connected to the national discourse of Swedishness. ${ }^{10}$ Sweden can be said to represent a form of Nordic whiteness, that has been connected with a "pureness." ${ }^{11}$ In order to better understand the ways that whiteness permeates Swedish society, we need first to engage with ways that this fluctuates over time, takes colorblind expressions, and struggles with finding a language to describe racial matters.

\section{Sweden and the Ideology of Colorblindness}

Sweden has been characterized as a white, colorblind nation in crisis that struggles to accommodate non-whites within its national imaginary. ${ }^{12}$ The inability to see race and speak of it in the Swedish context clashes with the existing societal diversity - Sweden has in the past decades become one of the states in the west with the largest immigrant populations. Less than $70 \%$ of Swedes are born in Sweden with Swedish-born parents, and out of Sweden's 10 million inhabitants, more than one million are born in Africa or Asia. ${ }^{13}$ In the meantime, Swedish society has, apart from become less homogeneous and white, had racist political forces consolidate into one of the biggest parties. Even though the far-right Sweden Democrats have in the past years striven to distance themselves from their original roots in Swedish Nazi and fascist groups, ${ }^{14}$ they are proponents of a stop to asylum migration and an increase in the 'repatriation' of immigrants as core political demands, ${ }^{15}$ and frequently mobilize racism against Muslims. ${ }^{16}$

Even when born in Sweden, Swedes who are racialized as non-white, not Christian, or having origins outside of the west, are called 'immigrants' or 'of foreign background' in societal discourses, while the word 'Swede' is used to imply whiteness. ${ }^{17}$ The inability to describe non-white Swedes as Swedes reflects tendencies to think that Swedes have no race (i.e. are white), and since non-whites are immigrants and thereby not Swedes, the Swedish nation is white (and has always been so). ${ }^{18}$ The erasure of the differences between race and ethnicity, i.e. whiteness and Swedishness, was partly due to the Swedish homogenizing nation-building project that took place during the first half of the 20th century, but also due to the colorblind anti-racism that made discussions on race and whiteness taboo in the 1970s and in the 80 s. $^{19}$ 
The homogeneous, white Sweden that is imagined as having preceded the immigration of the past decades, is sought for in the past. The longing after the imagined nation extends to visual media through an identified tendency to return to the Sweden of the 1950s and the 1960s in films and TV series. ${ }^{20}$ Nostalgic and melancholic aspects of Swedish fiction films have been connected to whiteness as a national symbol, while Swedish Roma and Indigenous Sámi, that do challenge the imagined homogeneity of the nation, have been portrayed as less white than other Swedes. ${ }^{21}$ Apart from racialized ideas that centre whiteness, Swedish national imaginaries of the 50s were constructed as gendered, as exemplified in the (televised) beauty contest Miss Sweden launched in 1949. In a time of parallel inward-looking nation-building and internationalization, the contest had a function of both broadcasting the Swedish national imaginary abroad, while gathering the Swedish nation domestically. The ideal (white female) representative was sought for all over the country, implying "that Swedish femininity is potentially present anywhere in the national space, and that the qualities of this femininity are competitive in relation to other nations." 22 Present-day reality romance TV shows then provide a novel venue for investigating gendered and racialized ideas on the nation - not least in relation to shows centring farming and rural areas as venues of 'authentic Swedishness,' and shows centring mobility in ways that discursively define the borders and boundaries of the nation.

\section{Whiteness in Reality Romance Television}

Reality television has regularly been exposed to questions of race both in scholarly and journalistic discourses. Issues of (mis)representation, diversity, and exclusion have been featuring in discussions around the racial realities represented in reality TV, with an emphasis on the anglophone context, and the US in particular, where race and racism are foundational elements of states founded on Indigenous dispossession, European settler migration, and transatlantic slavery. Relevant literature has covered issues such as the coding of non-white participants according to African American stereotypes, ${ }^{23}$ as well as the more general narrative structure of reality TV that addresses the Other as a source of entertainment, ${ }^{24}$ and frequently resorting to tropes of difference and conflict that perpetuate problematic racial representation and invisibilize the lived experiences of racism. ${ }^{25}$

At the same time, reality television has often been described as evidence of a post-racial era, aligning with mainstream media discourses that tap into "visions of a society that has already reaped sufficient benefits from the civil rights-movements of the mid twentieth century and needs no more government or social activism to achieve equal opportunity." ${ }^{26}$ Empirical research, however, continues to debunk the myth of post-racial ideology by demonstrating the spectacularization of race as a constituent element of reality television, even in cases where whiteness is explicitly addressed in relation to race. ${ }^{27}$ As such, reality TV plays an important part in constructing racial realities and sustaining racial hierarchies.

Within this body of critical perspectives on race (and racism) in reality television, of particular interest is the criticism specifically addressed towards the reality romance television sub-genre and its flagship, the 'Bachelor Industry,' including The Bachelor, The Bachelorette and related spin-offs. ${ }^{28}$ The Bachelor franchise has been shown to privilege whiteness both in overt and subtle ways, establishing a universe where the presence of people of color is merely instrumental; they exist just to "facilitate the process of two white people finding love." 29 By privileging white bodies and white love, The Bachelor franchise has been said to validate the naturalness and desirability of whiteness, ultimately telling a very specific story about romance: that "whiteness is essential to finding a romantic partner." 30

The critique of being 'too white' has accompanied programmes belonging to The Bachelor universe for some time, focusing mainly on the persistent whiteness of the bachelor/bachelorette leads, as well as the somehow always early elimination of non-white contestants, ${ }^{31}$ leading to popular criticism regularly discussing The Bachelor's "diversity issue" 
and "racism problem." 32 Some critics have emphasized the predominant whiteness of the show as a more general ideological layer, translated into some sort of "white gaze." 33

Similar critique has been targeting Farmer Wants a Wife, a reality romance show based on a similar premise but placed in a rural context. Sited in a "rural idyll," ${ }^{34}$ Farmer Wants a Wife, in its various localized versions, ${ }^{35}$ follows farmers on a hunt for love. This takes the form of multiple (individual and group) dates until the farmers identify the one person that they have stronger feelings for, often considering their suitability for life on a farm. Accusations of being 'too white' have targeted the programme throughout the years, ${ }^{36}$ with the most recent version of the Australian rendition being particularly criticized for its "shameful lack of cultural, racial and sexual diversity in the casting" (Figure 2). ${ }^{37}$

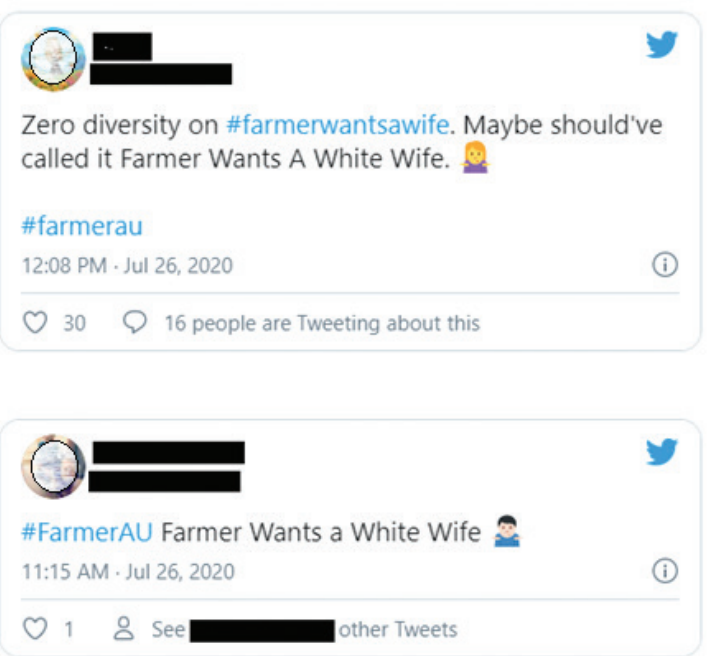

Figure 2. Twitter commentators criticizing the lack of racial diversity in the 2020 season of the Australian Farmer Wants a Wife (Source: Buzzfeed).

Drawing from the above discussion of two of the most representative and globally successful franchises, The Bachelor and Farmer Wants a Wife, reality romance television, emerges as a fruitful locus for the exploration of question of race, especially through a critical approach on whiteness, both in terms of representational politics and questions of inclusions/exclusions, but also as a logic crosscutting the whole genre.

\section{White Mobilities in Bonde Söker Fru - Jorden Runt}

In the sections that follow, we channel the discussions about whiteness in reality TV and Swedish colorblindness toward a critical investigation of Bonde Söker Fru - Jorden runt. We argue that the show provides an avenue to explore colorblind silencing of whiteness, border privilege connected to whiteness, and the increased significance given to national belonging in the contemporary era of (white) hypermobility. However, it should be noted that we are not criticizing individual people's behaviour; the critical enquiry is directed to the ways that television stories embed questions of race and package whiteness for/as entertainment. As such, our analysis focuses on the narratives constructed by reality TV and visual/editing strategies employed, as we have no knowledge of the potential difficulties 
or border restrictions that the participants actually faced. While reality romance shows like Farmer Wants a Wife are not entirely scripted, the filming and treatment of participants within a "structured and managed setting" 38 of a (formatted) reality show, allows much space for manipulation across pre-production, production, postproduction, and post-transmission. ${ }^{39}$ To a great extent, the power to represent lies in the hands of the producers, as they are the ones who possess ultimate control of the 'story.'

Bonde Söker Fru - Jorden Runt rotates between four geographical contexts with different relations to whiteness: Firstly Sweden, as the country of origin of both the farmers and the wanted love partner, as well as a site of circular or seasonal (return) migration. The three countries of destination are Spain, part of the EU free mobility as a Southern European state, Australia, an Anglo-Celtic settler colony, and Mozambique, a former European colony in Sub-Saharan Africa. While Australia commonly is conceptualized as being part of the Global North/ Western world, we take a historical perspective where (white) settler migration to Aboriginal lands is viewed as North-South (settler) migration, of which present-day migration is a continuation. The premise of the show is the farmers' wish to find someone to share their life with who is Swedish.

The analytical sections that follow provide a detailed presentation of the farmers' living and working environment, as well as the lived realities and experiences of the participants. The analysis highlights important discursive/visual ingredients that illuminate expressions of white mobilities, exemplifying the 'race work' performed by the show.

\subsection{Whiteness Abroad as a Permanent State of Tourism}

The first geographical context that figures in the show is southern Spain, focusing on the life of Leif, a 69-year-old Swedish avocado farmer. In general, the Spanish context is filled with meaning for Swedes, with many viewing it as a holiday destination, as a site for circular migration, or settlement upon retirement for escaping the cold weather of the North. Since Spain is part of the European Union, mobility is made relatively easy for Swedes wishing to live in Spain. Migrating from Sweden to Spain, nevertheless, contains a North-South dynamic embedded in whiteness. The imagined position of Spain as a southern nation contributes to the accentuation of whiteness among migrants from Northern Europe that form (white) colonies in the South. An 'orientalization' occurs between the 'pure whiteness' of the North and the South connected to a lack of rationality, responsibility, and productivity, ${ }^{40}$ in contrast to the North. The white communities can be transnational, including Britons, the Dutch, Nordics, and Germans united by a common northern identity. It has been found that 'international' social networks in Southern Spain are structured by a whiteness perceived as neutral, "guided by ideas of cultural similarity and parallel difference driven by neocolonial orientations that divide northern European whiteness from its southern counterpart." 41 Hence, even though Spain could be described as a white European nation, ${ }^{42}$ a clear scaling of whiteness can be identified between the Northerners and the Spaniards.

What is more, Spain and Southern Europe hold an imagined position as a holiday destination for Northern Europeans, which survives even when settlements of a more permanent character are formed. When maintaining elements of tourism, a segregation characterized by little interaction and low immersion in local culture can be identified as contrasted with integration and local embeddedness. Many Northerners live in separate colonies with their own schools, hospitals, and social institutions. Such communities free the migrants from demands of integration identified as an important policy of border control that extends not only inside but also beyond the territorial border. ${ }^{43}$ Instead, the permanently, or periodically settled Northern European migrants live a life that resembles a permanent state of tourism.

In the show, we follow a 69-year-old Swedish avocado farmer settled in southern Spain (Figure 3), near Málaga, who is presented in the following way: 
G. Aitaki and N. Carlsson, Farmer Wants a (Swedish) Wife

Leif, 69, is the widower and family father who dreams about someone to share his life with. He is full of sparkling, lovely energy and loves cooking, carpentry, and working in the garden. The favourite season on the farm is January when tons of avocado are harvested. He describes being in love as the best feeling in the world and longs for feeling it again!

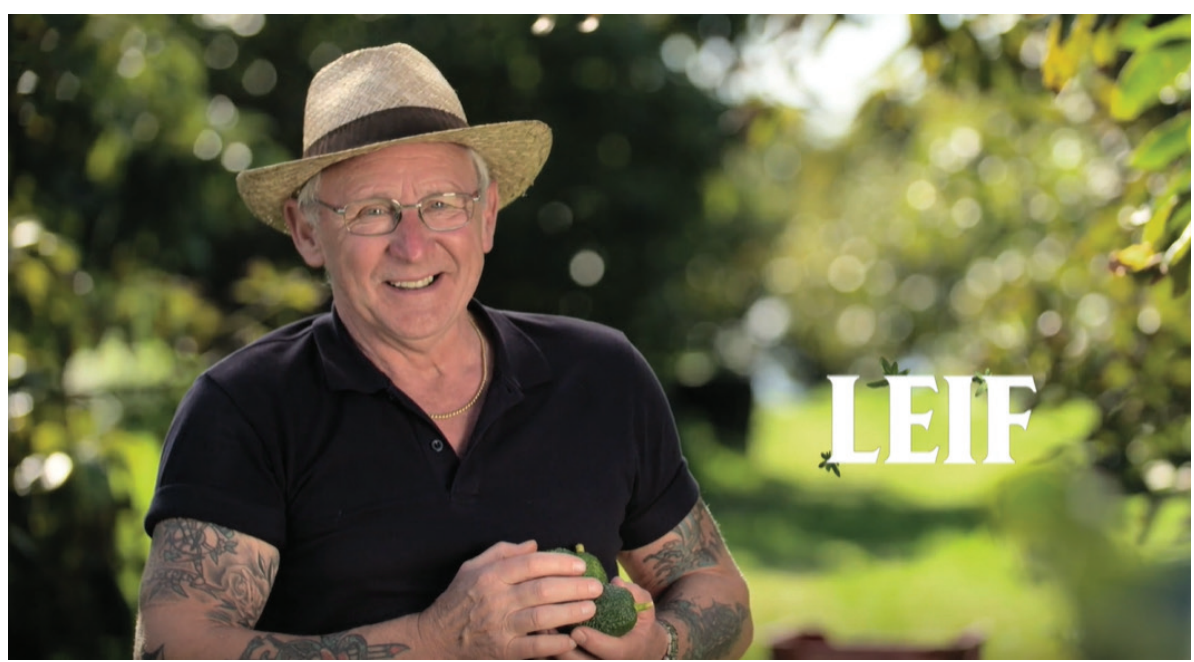

Figure 3. Leif, the avocado farmer, based in Spain.

Leif (retired in Sweden) is in fact a circular migrant who lives both in Sweden and in Spain, in line with many Northerners who reside in Southern Spain during the colder periods of the year. In the pitch of the show, references are indeed made to the sunny weather, and Leif spending harvest time in Spain and the rest of the year in Sweden. The motivation for cultivating avocado (and mango) is not explained in the show, neither is the decision to settle in Spain, in a 3-floor villa with a pool overlooking the sea.

Snapshots of Spain as a multifaceted country of destination and practical aspects of potential settling down do not appear to be part of the narrative. Instead, it is the 'tourist gaze' that permeates Leif's story as a whole, particularly in terms of how the potential 'wives' get to test-drive living abroad. The arrival of the Swedish women and the enthusiasm about travelling to Spain is communicated to the viewers through footage from the aircraft and the airports, with ABBA's Chiquitita sung in Spanish as musical background, to mark the transition between the two geographical contexts. Upon their arrival on the farm, the women are depicted immediately becoming mesmerized by the natural surroundings, admiring the citrus fruit ("Look at those lemons!," one of them exclaims in an ecstatic tone). Reunited with Leif, the women appear quite impressed with the living conditions, the spacious villa, and the swimming pool, leading one of them to exclaim "I can imagine living here" - without even having the opportunity to actually experience life in Spain, as well as the daily life on a farm. 


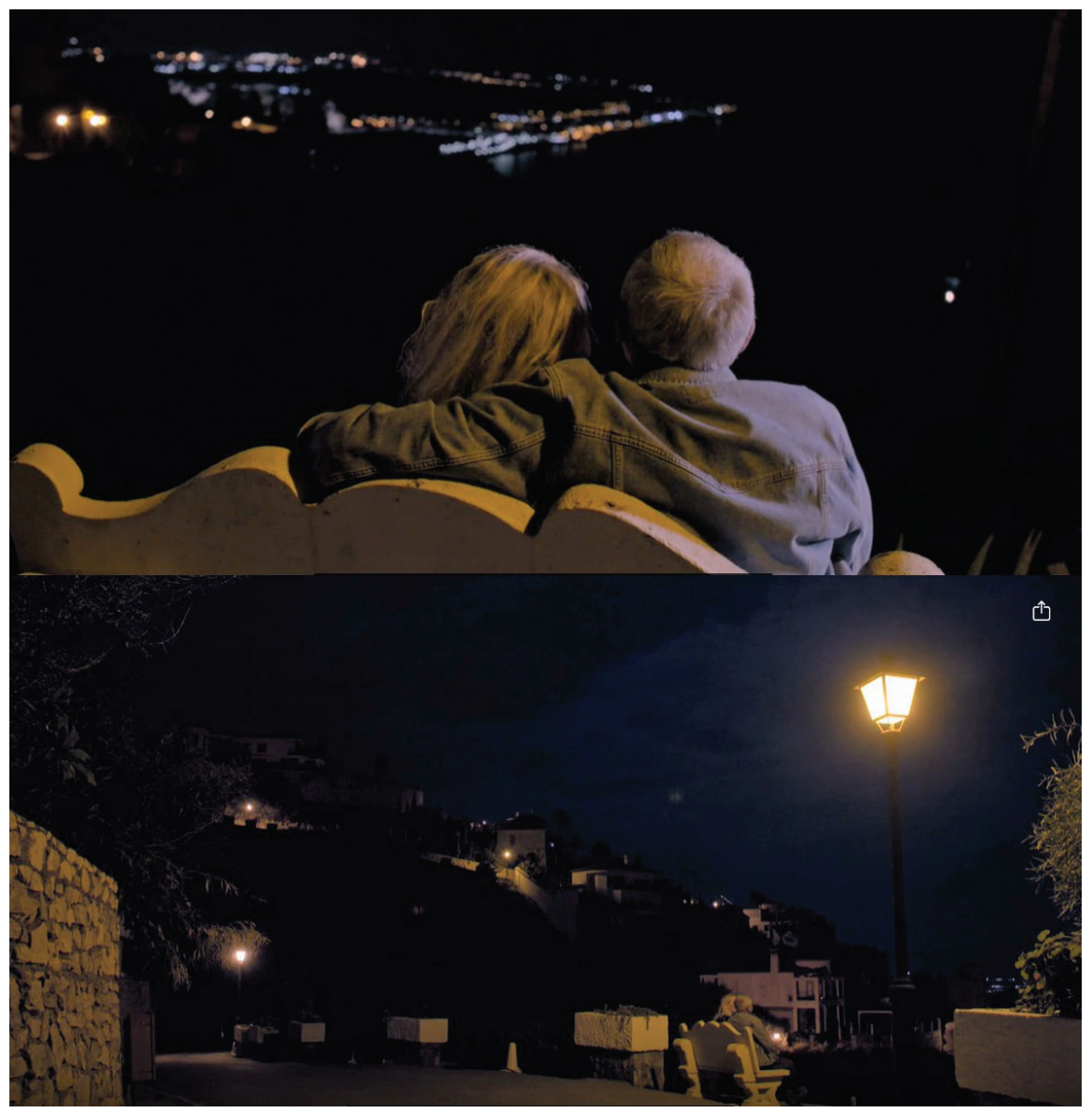

Figure 4. Romantic views through the tourist gaze.

The tourist gaze remains active throughout Leif's story defining the kind of experiences that the incoming women acquire from life in Spain, contributing at the same time to the popular imagination about what "moving to the South" looks like. In fact, the four women who were chosen to travel to Spain are enthralled by the settings Leif lives in, although their experience is completely restricted to Leif's house, fields, and occasional romantic dates. Inside the house, the women enjoy a comfortable interior as well as magnificent terrace views while they read books or have a glass of wine. Outside the house, the viewers witness the women and Leif going on dates and reveling in romance in picturesque surroundings, connoting warm and peaceful moments in the exotic South (Figures 4 and 5).

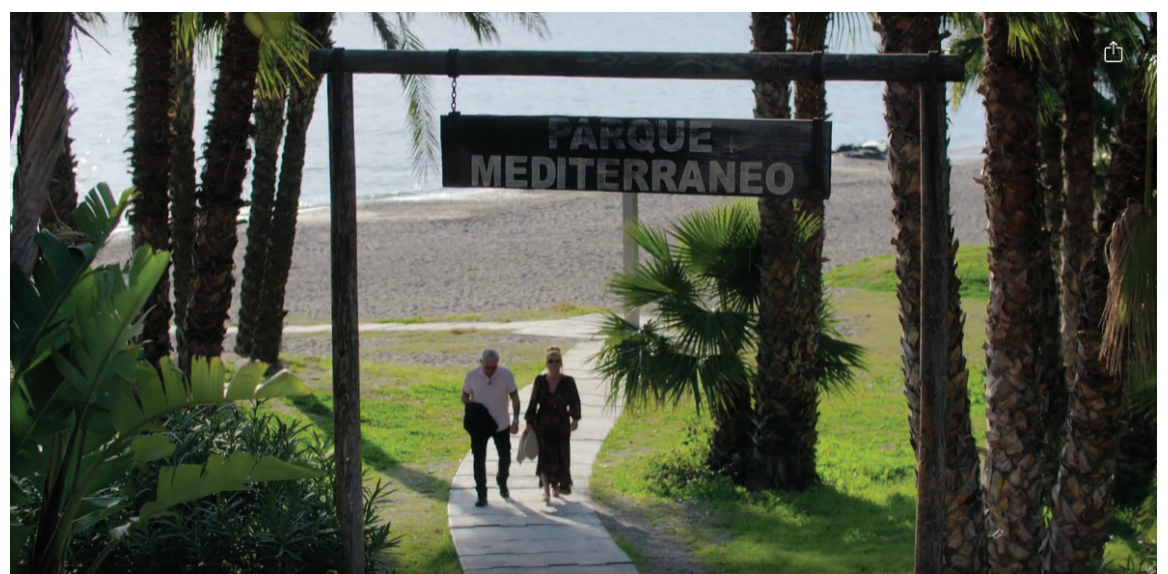

Figure 5. Romantic walks through the tourist gaze. 
Interestingly enough, a similar logic also characterizes life on the farm itself. As is often the case with the farmers on the show, the three farmers taking part in this version are interested in testing the compatibility between the potential wife and life on the farm, a factor that can significantly influence a decision regarding a common future. In the case of Leif's story, life on the farm is presented in the form of activities that resemble the logic of agrotourism, with the four women engaging in relatively light tasks (such as picking avocados from trees, placing them in lugs, and planting saplings) and Leif acting mostly as a host/guide, explaining different processes, assigning small tasks and, basically, making sure that everyone is having a nice time. In episode 4, Leif and the women engage in some arts and crafts, providing a complementary visual layer of agrotourism, a playful element in the imagined experience of living on a farm (Figure 6).

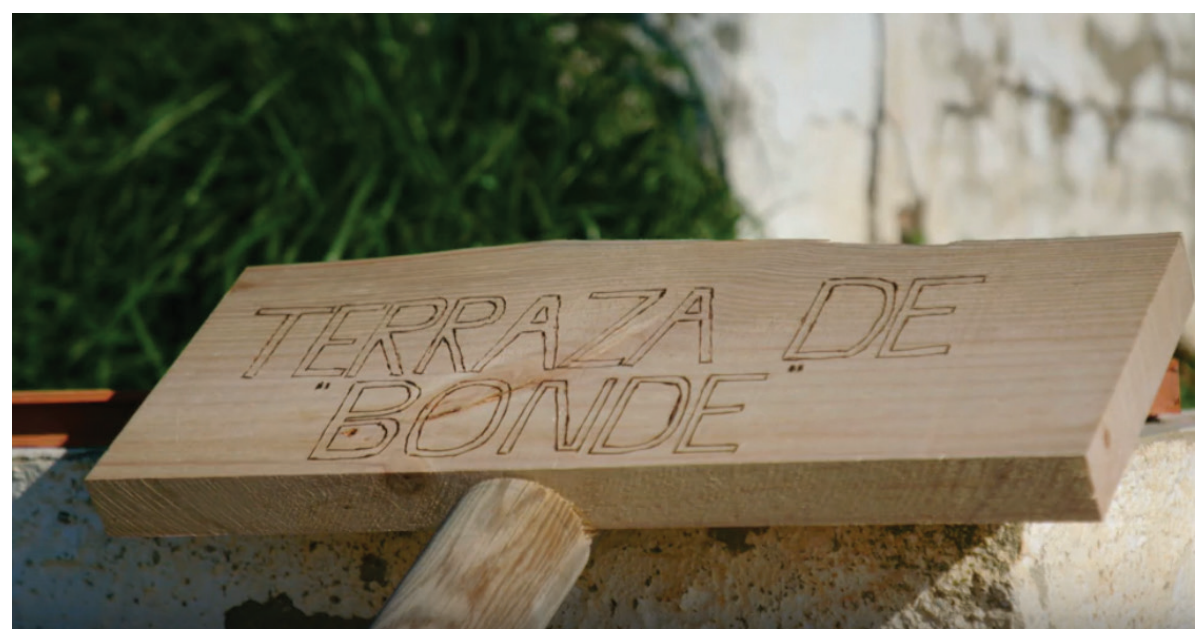

Figure 6. Arts and crafts as part of the agrotourism experience.

As the tourist gaze is established as the primary mode of 'experiencing' Spain, specific meanings are assigned to border crossings: a temporary character and clear intention to return 'home,' and a leisure activity associated with pleasure, daydreaming, and fantasy. ${ }^{44}$ The discursive and visual elements discussed above point to an equation of life in Spain with a permanent state of tourism. At the same time, significant absences, such as local people and community life, intensify the representation as a kind of tourist bubble and, as such, disconnected from the complex realities of moving and adjusting to life in another country and culture.

\subsection{A White Adventure in Terra Nullius}

The second geographical context that figures in the show is Australia, an Anglo-Celtic settler colony founded on January 26, 1788 by a British captain shipping British convicts to the colony. The colony was founded on Indigenous territories where one of the oldest civilizations in the world -60,000 years - was still thriving. A violent colonization, displacement, and erasure of Aboriginal and Torres Strait Islander communities resulted in present-day Australia, a settler colony largely inhabited by descendants of white British and European settlers, for which whiteness was foundational. During the White Australia policy (1901-1973), migration from white countries in Europe was facilitated while preventing the migration of Pacific Islanders and Asians to Australia. Indeed, while Chinese were kept out through official policy, Scandinavians were considered ideal colonists; their arrivals were subsidized and lobbied for:

In practice there have only been two major periods of Scandinavian migration to Australia - from 1870 to 1892 and from 1954 to 1971. In both cases generous assistance was available, conquering cost and distance. Such assistance has not been available to anyone other than refugees for fifteen years nor is it likely to be restored. ${ }^{45}$ 
Since the colonization of Australia, Swedes have indeed been viewed as attractive settlers. Importantly, the barriers for migrating were not only removed, but actively mitigated to alleviate the costs of migration. Thereby, present migrations between Sweden and Australia can be connected to the foundational policies of white settlement where Scandinavians enjoyed a borderlessness that was not available to non-white, or less white, settlers and migrants.

Fast-forward to today, the second farmer we follow in the show, a Swedish man working as a meat farmer in Australia since 2017 (Figure 7), is introduced in the following way:

The charming 31-year-old Andreas from Värmland got tired of the winter cold at home in Sweden and moved to Australia, where he got a job at a farm as a meat farmer. He describes himself as kind, helpful and stubborn. Recently, he has started to miss someone to come home to and he feels more than ready to find the love he one day can start a family with.

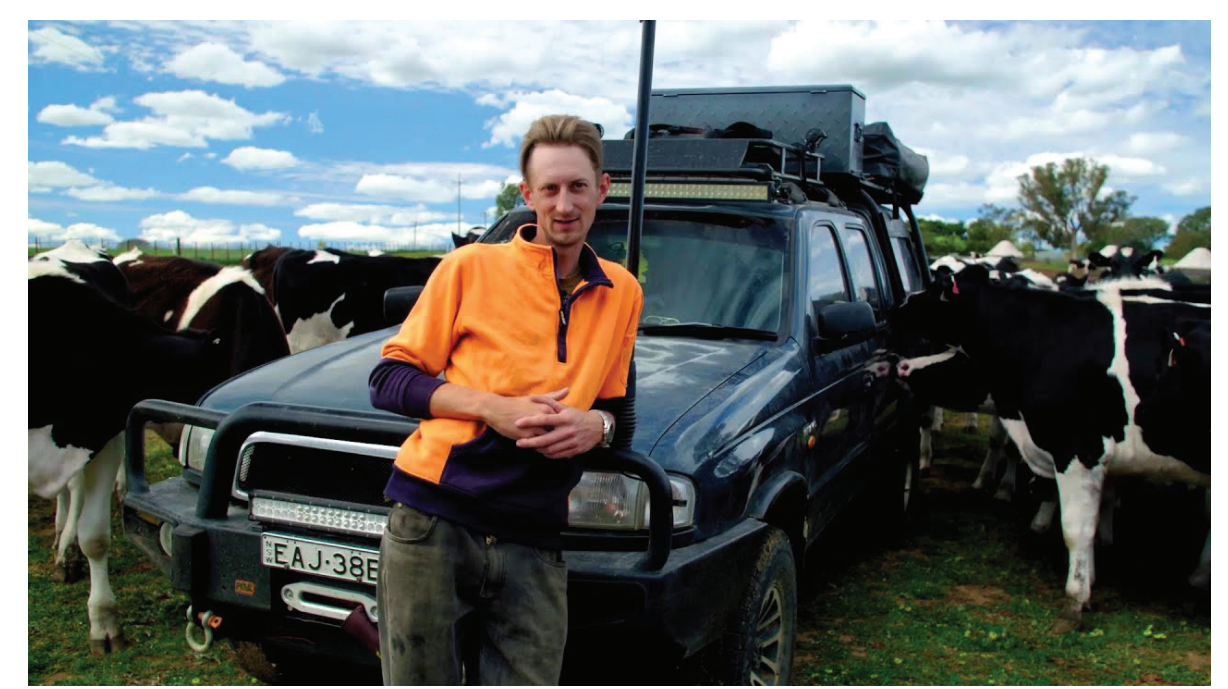

Figure 7. Farmer Andreas who moved to Australia because he was tired of Sweden's cold weather.

The story of farmer Andreas is presented as part of a rather uncomplicated continuum of smooth transition despite the exclusionary history of migration to Australia. The major incentive for his move from Sweden is, simply, warmer weather. As he states in the casting episode: "The feeling when you go out in the morning, you hear the birds singing, the sun is up, you feel the warmth, you feel that you did the right thing." Furthermore, he describes his migration as a "chance" of going to Australia to do the same thing he was used to doing at the countryside where he grew up in Sweden. Thus, we are presented with a discourse of border-crossing that is not characterized by any sort of consideration or anxiety regarding travelling, working, and establishing himself in a new country; rather the dominant discourse appears to tap onto a context of relatively free mobility that resembles a kind of study or work abroad opportunity, and thus primarily motivated by choice.

Interestingly enough, this representation of an unproblematic passage to Australia does not agree with previous reality television negotiations of border-crossings. Compared to Border Security: Australia's Front Line, a reality TV show focusing on border policing and control, with border crossings being mostly connected to discourses of (illegal) immigration and (national) security, our case appears to completely erase the strictness of monitoring and control, as well as the complexity of moving to Australia in terms of psychological burdens or pragmatic obstacles (visa, money, authorities). 
What the stories of Andreas and Leif have in common is the temporary character of the border-crossing, as well as the fact that both of them are guided by mobility-related questions in seeking a wife. However, as Andreas' life in Australia is significantly less glamorous than Leif's life in Spain, the temporariness of the situation is based on the plan to eventually return home. Hence, in contrast to the unidimensional US reality TV show 90 day Fiancé, ${ }^{46}$ the farmer here has the possibility of actually choosing the country of settlement while maintaining the possibility to move back home and, unless they wish to, never return to Australia even if he starts a family there - with a Swedish wife. Andreas motivates his lack of interest in dating Australian women thus:

The first reason why I want to meet a Swedish girl is that then one is better prepared for the future because in case something happens at home one can leave. Had I had an Australian girl and something happens, she would have her life here. If I could not come back, then it breaks.

Although the reality of working on a farm is not as romanticized as in the case of Leif and Spain, a closer look at the settings of this version of the rural romance provides valuable ideological entry points, especially in terms of how Australia is repackaged and reimagined as a geopolitical and historical entity. Two key elements are of significance here. The first one concerns the repetitive visual framing of Andreas' story with imagery that emphasizes the vastness of empty land, the absence of people, and the possibilities for extensive farming. Extreme long shots provide panoramic views of the land, establishing Australia as a, more or less, empty land (Figure 8). The ideological work in progress here is particularly important, taking into consideration that Australia was treated by the British colonizers as 'Terra Nullius,' unowned land, as part of the doctrine of discovery, allowing and facilitating the violence of European settlement.

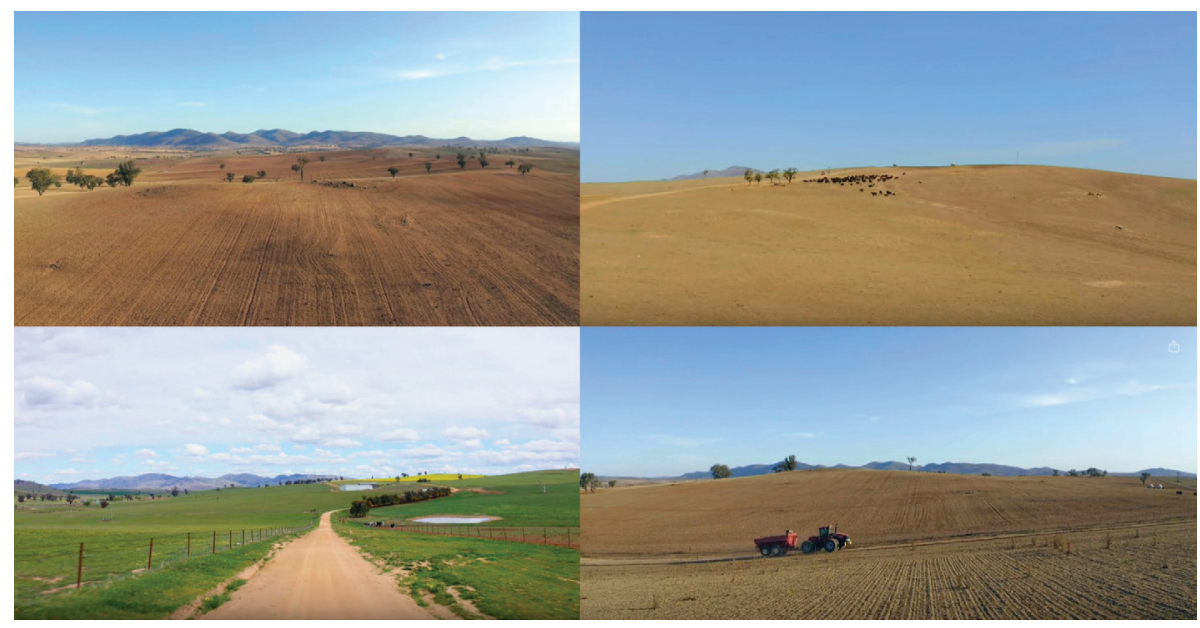

Figure 8. Imagery that accentuates the 'Terra Nullius' discourse.

Connected to the above, a second element concerns the incorporation of Australia Day as part of the white experience abroad. In episode 5 (Figure 9), the remaining three women together with Andreas go out to celebrate the day, which marks the anniversary of the 1788 arrival of the First Fleet of British ships at Port Jackson, New South Wales. Although the character of Australia Day has evolved throughout the years and has been rebranded as a celebration that reflects the diversity of contemporary Australian society, the anniversary itself remains a highly controversial topic, as it excludes and erases Indigenous populations, while commemorating an act of white invasion. In fact, Australia Day is also referred to as Invasion Day, Survival Day, or Day of Mourning, with Indigenous Australians and allies demanding abolishing it entirely. Within the show, the history of Australia, the complexities of its past, and even the controversies of the present are completely absent. Instead, Australia Day is presented as an unproblematic day of celebration, an opportunity for the visiting women to get a closer look at the traditions of the local culture, and a chance for some relaxing time off the farm. 


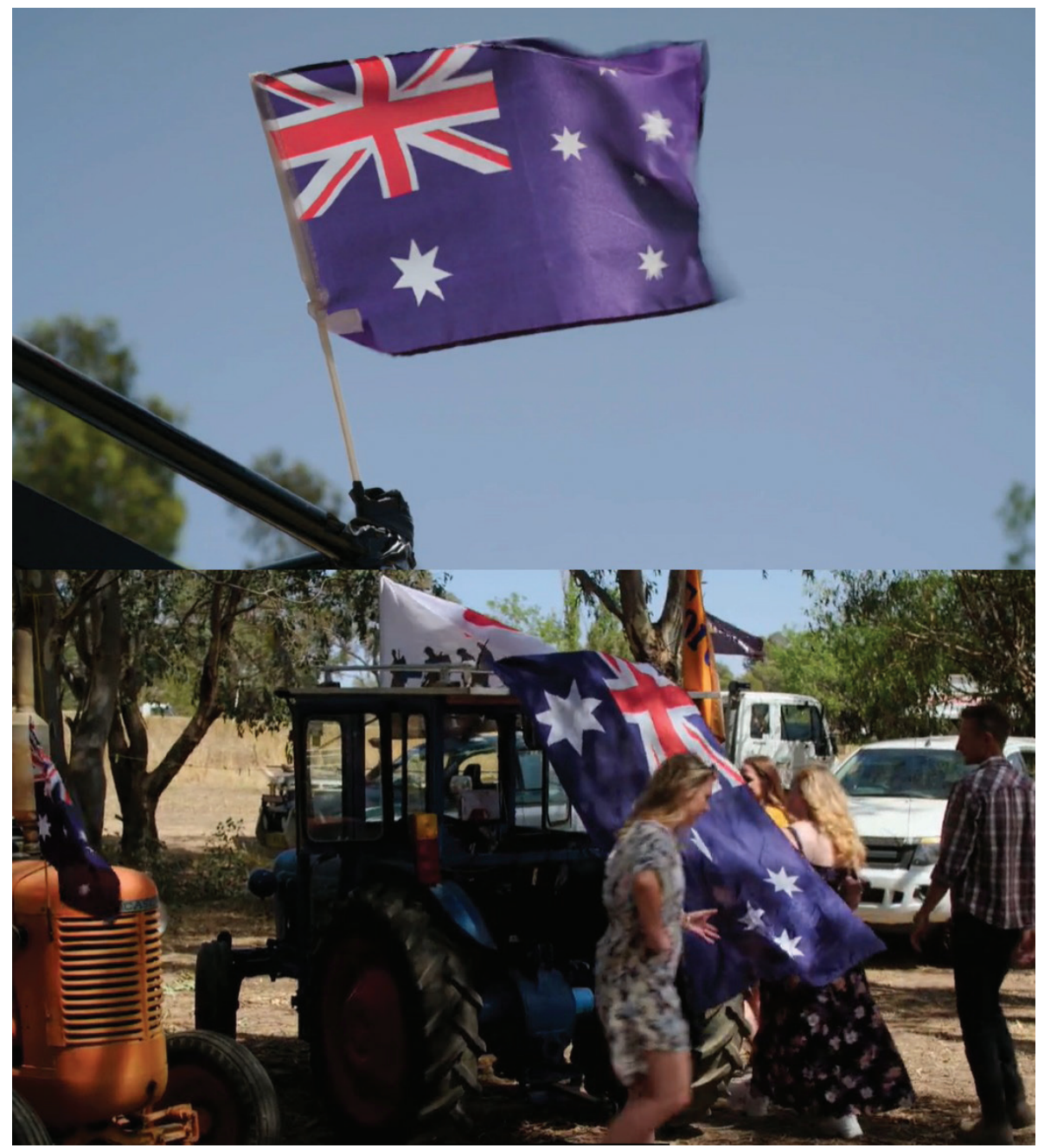

Figure 9. Australia Day and the (unproblematic) celebration of a white nation.

The absence of local people is noteworthy in the case of Andreas' story as well. Andreas is depicted as living a relatively lonely, cowboy-ish kind of life. The ideological parameters of this absence align with the aforementioned dominant (white) narrative emphasizing the settler colonial imaginaries and hegemonic whiteness, making contemporary migration for Europeans smooth, accentuating Australia's settler colonial project as successful.

\subsection{White Saviourism in "Paradise"}

The final geographical context of the show is Mozambique. Rather than a white settler colony, the country is an independent, post-colonial nation-state that gained independence from Portugal in 1974, after nearly 500 years of colonization (1498-1974). Like other white minority rulers of African colonies, Portugal had apartheid laws in place. ${ }^{47}$ After decolonization, Portuguese (white) migrants have been shown to distrust Mozambicans, getting highly skilled positions even when not qualified, as semi-skilled, and not mixing with local people. ${ }^{48}$ As part of the white, civilizing, colonial hegemony, ${ }^{49}$ Swedish migrants in Mozambique enter a context of whiteness, even though they lack the accumulated power of the former colonizers. 


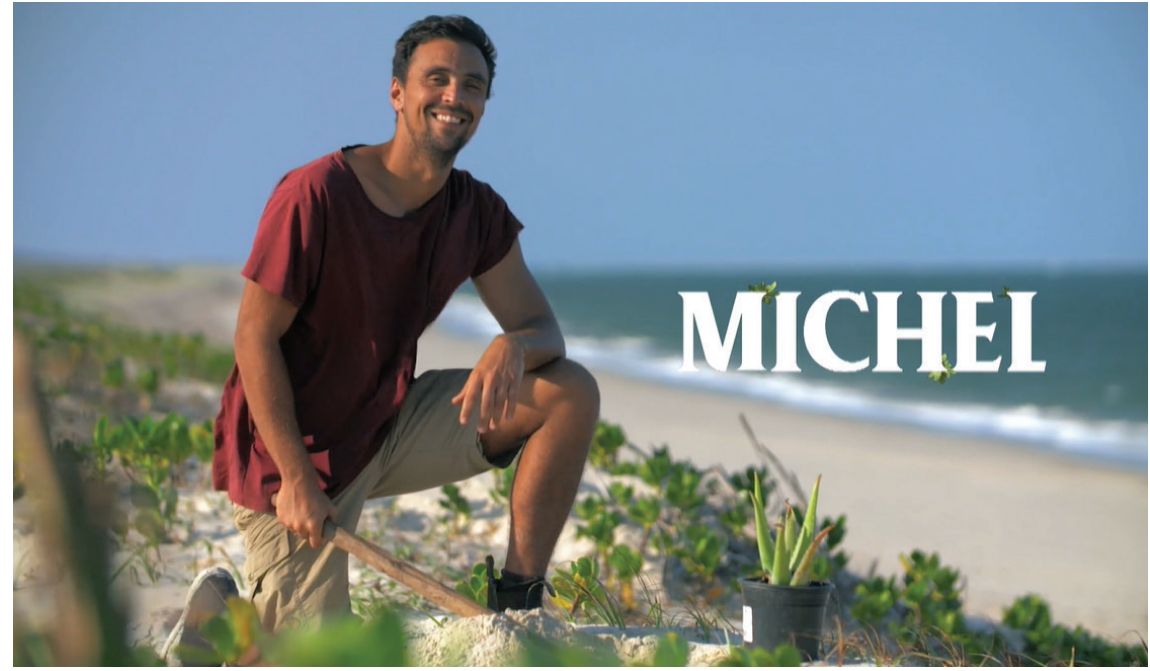

Figure 10. Michel, the Mozambique-based farmer.

The farmer we follow in the show is Michel (Figure 10), a Mozambican-Swedish vegetable farmer, is introduced at the start of the segment thus:

Michel is 34 and says he is single due to focusing on his own dreams - now he wants to find someone to share them with. He was born in Mozambique but has a Swedish father so when he grew up he commuted between the countries. Today he runs a farm where he produces fruit and vegetables. Apart from the farm he has a passion for charity and works to provide better opportunities for people in the area.

The presentation emphasizes that he is not "too" Mozambican but actually has grown up in Sweden too. Interestingly enough, only his Swedish parent is mentioned. The use of 'but' as a conjunction communicating contrast is particularly noteworthy, marking the beginning of a discourse that is later repeated by the female participants whether explicitly or implicitly, and that accentuates his somewhat ambiguous position being of mixed heritage, in-between two countries. Indeed, mixed-race persons often experience exclusions from both communities of descent, at the same time as there is a great variation in the contextual expressions of their experiences. ${ }^{50}$ Whereas Michel possibly would be perceived as non-white in Sweden, in a Mozambican post-colonial context his Swedish citizenship, surname, white father, and circular migration between Sweden and Mozambique, would put him in proximity with whiteness. Indeed, in the show, he is discursively constructed as part of Swedish whiteness, yet with some elements of hybridity ${ }^{51}$ constantly present. Michel continuously explains that he always felt in-between cultures which has translated into a lifestyle of circular migration, with frequent trips between the two countries. This kind of life becomes the primary criterium for choosing a partner. For example, when the show hostess asks Michel how come he is still single even though he resides in such a 'paradise,' Michel responds with a vague 'it is not easy to find someone' reaction, adding that he wishes to be with someone that understand what it means to live abroad, without him mentioning dating local women. As such, Michel embarks on a mission to find his special someone among four women who, in one way or another share Michel's lifestyle and feeling of rootlessness: for instance, Yohanna describes herself as being born in Sweden but having always lived her life between Sweden and Mexico; and Ida is currently involved in humanitarian projects in Nepal.

The aforementioned notion of Mozambique as a paradise is worth returning to. Apart from the hostess' initial reaction, the word 'paradise' is exclaimed by one of the women during the car ride on the way to Michel's residence, with another one observing in awe that 'there is so much to look at' (Figure 11). This automatic exoticization, a common visual and discursive mode for the representation of non-white geographical contexts, is a tactic that has its roots in colonial and racist discourses, and as such is connected to social practices related to othering, commodification, and exploitation. Apart from a power inequality, exoticization establishes a certain distance between the subject and the object of the process, often approaching the new environment with predefined attitudes rather than curiosity about unexpected 
experiences. Similar to the case of the women's transition to Spain, the arrival to Mozambique provides space for the activation of a tourist gaze over a 'primitive' - as the Swedish participants call it - way of life and the subsequent exotification reflexes. It is interesting to observe that the musical theme that accompanies the women's experiences (also sung by them during the car ride) is 'The Lion Sleeps Tonight,' a typical white stereotype of African culture.

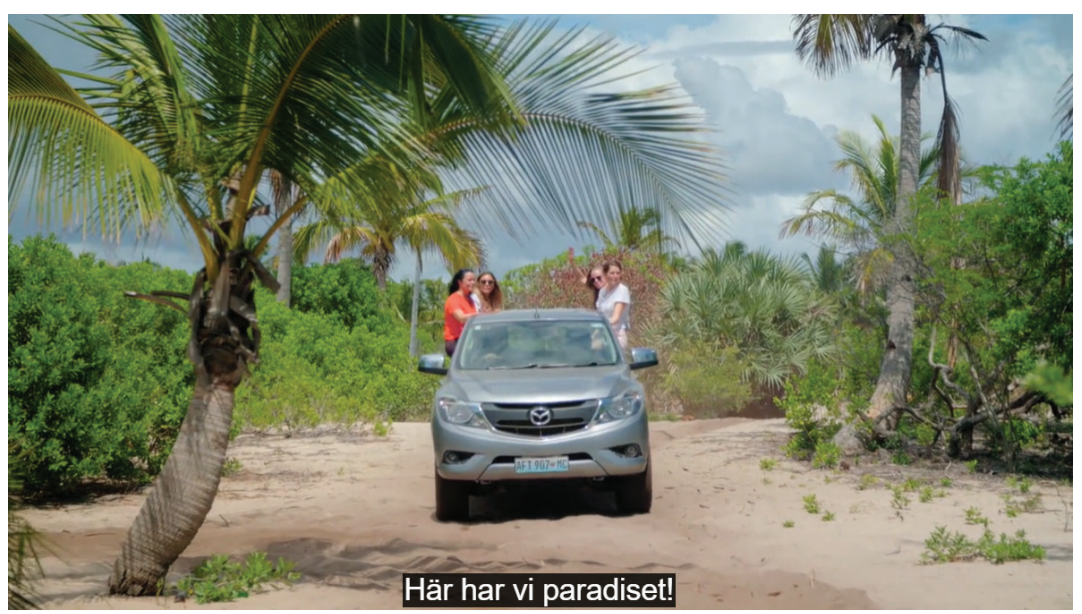

Figure 11. The arrival of the four women in Mozambique is accompanied by the exclamation "here we have the paradise".

Unlike the episodes set in Spain and Australia, the visibility of local people is marked. On the farm, the workers make an appearance, albeit rarely, and they mostly have an instrumental function. Two such appearances include instances where the visitors have accidentally locked themselves out or have dropped the bucket in the well and the workers are called by farmer Michel to take on the repair or solve the problem (Figure 12).

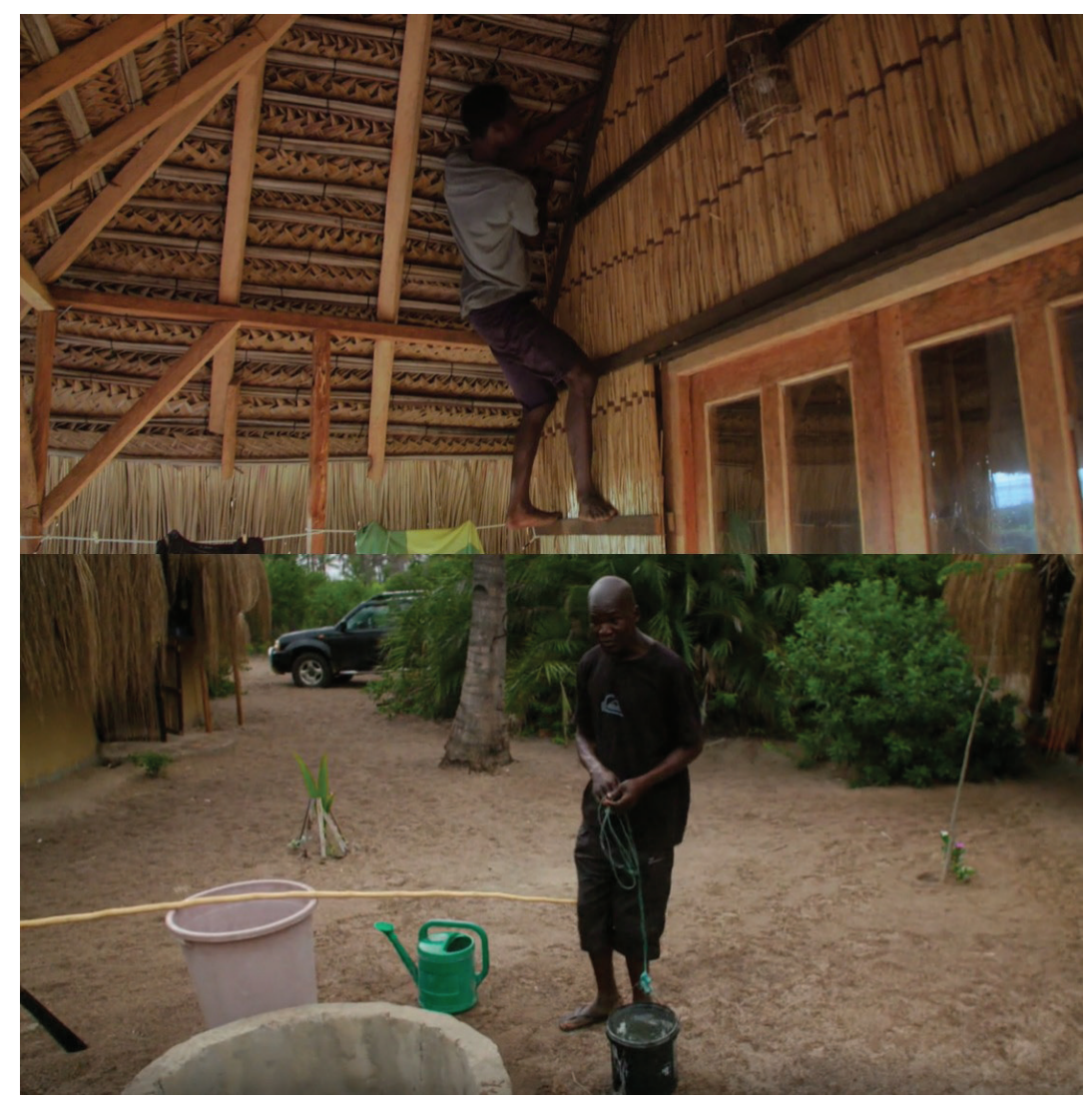

Figure 12. Local workers are called in to fix what the visitors break. 
Outside the farm, local people are included in the story to accentuate Michel as an important and well-established figure of the local community (Figure 13). In episode 4, Michel and the women go out shopping; this gives them (and the viewers) the opportunity to acquire a closer experience of life in Mozambique. Footage includes playful interactions of Michel with local people, centering on how well he can navigate the local context - with an emphasis on his command of Portuguese ${ }^{52}$ and the practice of making jokes. Apart from a tactic of courtship display aiming at appearing attractive to a potential mate, this visual framing of Michel as a central figure of the local universe allows (Swedish) whiteness to emerge as a positive influence for the local community.

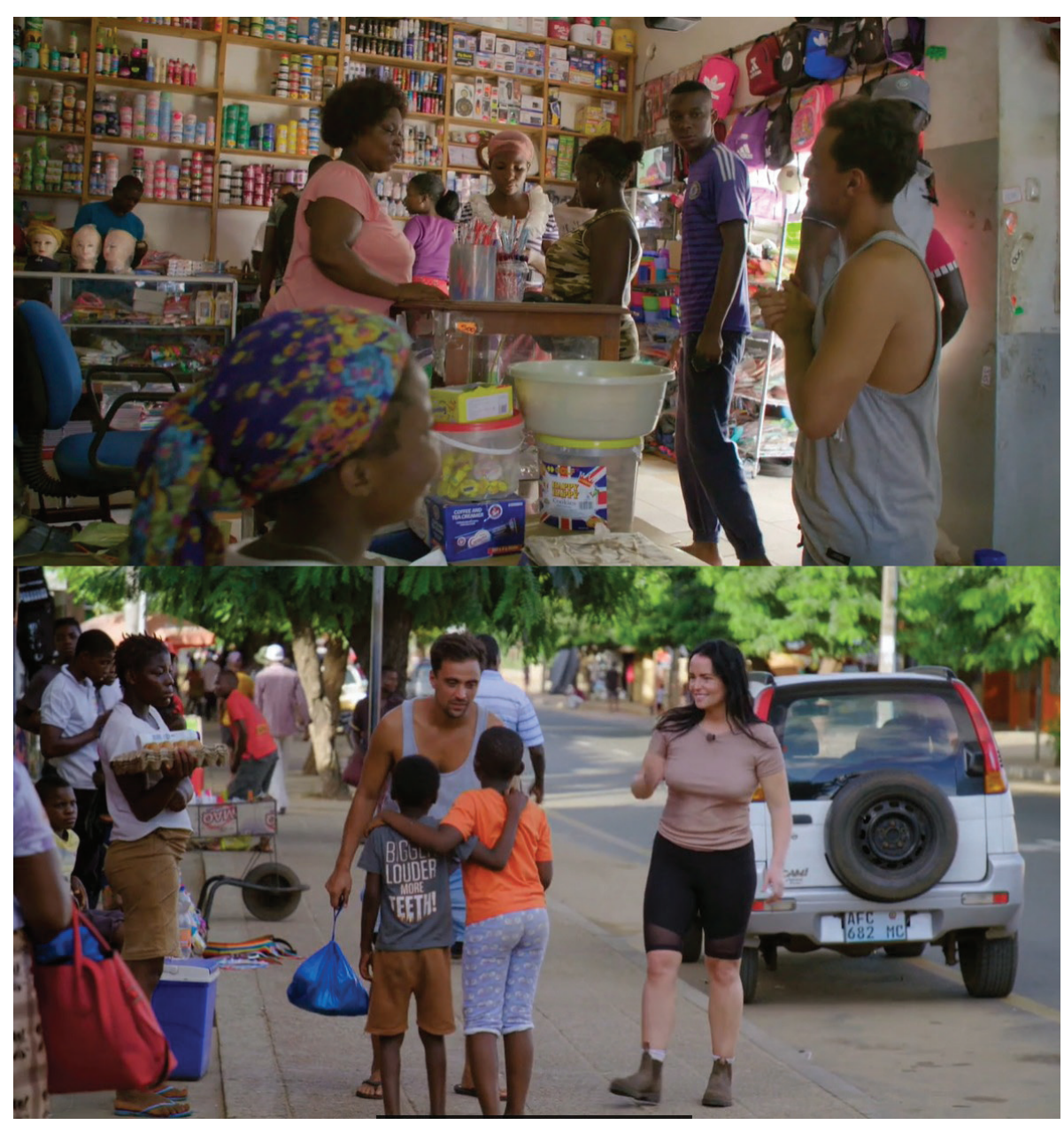

Figure 13. Michel is often depicted as a central figure of the local community.

As an extension of the above narrative, the story of Michel also includes a particular emphasis on the activities he engages in in order to 'help' the local community. An important part of Michel's life in Mozambique is dedicated to 'societal projects,' such as the construction of a maternity clinic in Linga Linga, aimed at aiding the locals in improving their living standards and Mozambique as a whole. Mozambicans are talked about as 'they,' people who for instance do not recycle (unlike 'us'), and, thus, a discourse of othering is reproduced. Michel also talks about how many opportunities he sees for his Swedish partner there - such as building a school, water system, electricity, agriculture, or training locals in entrepreneurship. The philanthropic discourses and ideas, that separate Swedes from local communities who appear in the form their benefactors rather than peers, equals, or colleagues, can be linked to practices of 'white saviorism.' Visually, this is complemented by a sequence in episode 6 editing together snapshots of local life in a way that resembles fundraising campaigns by international or domestic charity organizations commonly displayed in western countries (Figure 14). 


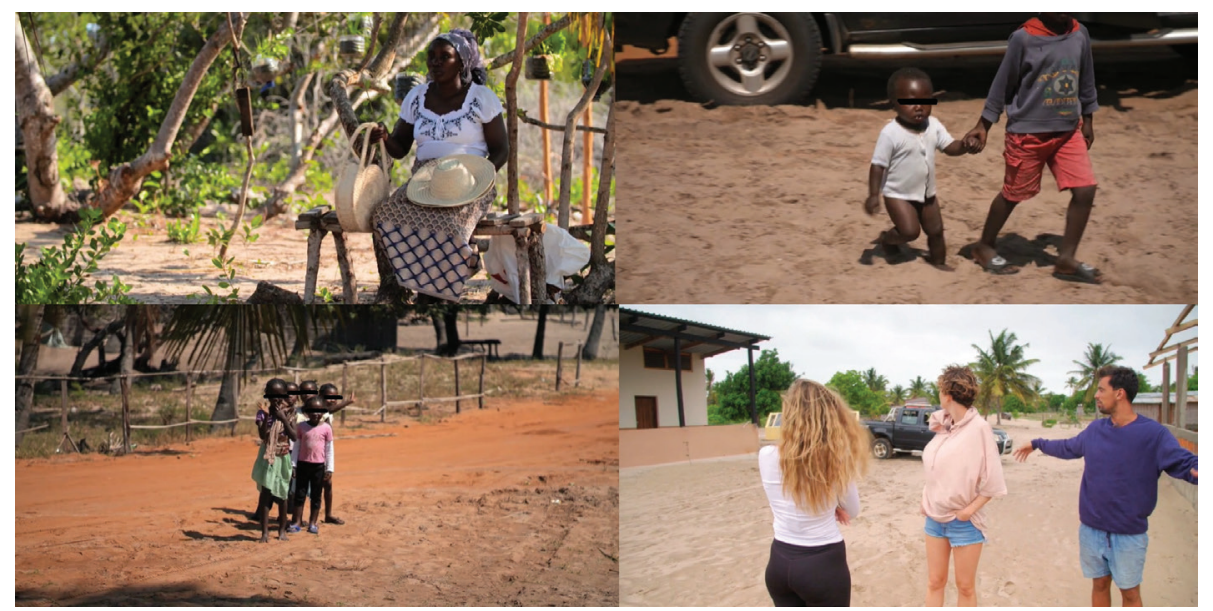

Figure 14. Fundraising imagery while Michel shows ongoing projects aimed at 'helping' the locals. ${ }^{53}$

\section{Conclusion}

Bonde Söker Fru - Jorden Runt offers three discursive versions of white mobility whose roots can be linked to colonial understandings of the world and racial hierarchies: tourist, adventurer, and philanthropist. All three positions involve extracting something from the local context - warm weather, land for farming, meaning through charity - but none of them require or involve local embeddedness, long-term commitment, and integration. In all three geographical contexts, the privileges of mobility manifested in borderlessness, or lesser barriers for integration or migration, can be connected to whiteness and Swedishness. In addition, a variety of discursive and visual practices provide important evidence about "how (white) people have and still are imagining complex relationships between various cultural and racial or ethnic groups." 54

In Spain, whiteness abroad is featured as a permanent state of tourism. The narratives offered reproduce the summer, ocean views, pools, and "exotic" fruits. The protagonists spend their time reading in the sun, living the typical holiday or Nordic retiree life. Migration is not intended to be permanent, but seasonal, and can be reversed at any time. It does not involve painful farewells of family and friends and struggles with adapting to the local habits, but allows a combined life in the North of Europe and in southern Spain.

In Australia, the border-crossing is presented as an adventure rather than a permanent life-changing decision. The local population is not featured, rather the life of the farmer seems solitary, amidst the vast land. No references are made to the strict border control in Australia, nor the Indigenous Australians that have been displaced from their lands by (white) farmers. The white Australian settler colony figures as an attractive, effortless destination for white migrants and an opportunity for adventure.

In Mozambique, we witness how globetrotters, third culture kids, internationally oriented, multicultural millennials with a sense of in-betweenness navigate the country. The intended love migration involves a plan to undertake a lifestyle circulating between Mozambique and Sweden. Mozambique, portrayed as a poor and primitive paradise, is embedded in a discourse of charity, while the local population is to receive help and development from the Mozambican-Swedish farmer and their partner. The local society is thereby not invisible but features as a development project, an object of charity, and thereby as a locus full of opportunities. White saviorism and othering are the dominant features structuring interactions and mobilities between the wealthy North and its former colonies, whose populations are excluded from Europe through strict migration barriers.

A fourth famer, Luigi, based in northern Italy, only figured in the 'casting' episode. He was subsequently withdrawn from the show since the production team did not deem his possibilities of finding love based on the letters received 
was high enough. This wine farmer was the most established in the 'foreign' context and identified mainly as Italian while explicitly wishing to meet a Swedish woman so that he can share everything Swedish with her. He had never lived in Sweden, had grown up in Italy with one Swedish and one Italian parent, spoke Swedish with a slight Italian accent, and had shared custody of his teenage daughter who did not seem to speak Swedish. Even though he only figured in one episode, his segment featured a considerable part of the portrayals of the local population and language in the entire show. This was the farmer that had the biggest stakes to leave the country, and the clearest bond to the 'foreign' context. Thereby, the fourth, unfeatured and excluded farmer differs from the other three: love migration would not have been temporary but permanent, would have involved local integration, and would have made Swedishness a side identity rather than a central one. By perpetuating racial hierarchies, invisibilizing white privilege and obscuring the complexities of border-crossings, the Swedish reality romance TV show Bonde Söker Fru Fru - Jorden Runt depicts white mobility as a relatively smooth process of movement through the figures of the tourist, the adventurer and the philanthropist.

\section{Acknow le dge ment}

The authors would like to thank the anonymous reviewers, the issue editors, and our colleagues for their constructive comments.

\section{Notes}

1 Rachel E. Dubrofsky, "The Bachelorette's Postfeminist Therapy: Transforming Women for Love," in A Companion to Reality Television, ed. Laurie Ouellette (Chichester: Wiley Blackwell, 2014), 194.

2 Mimi White, "Ideological Analysis: Television and Contemporary Criticism," in Channels of Discourse, Reassembled: Television and Contemporary Criticism, ed. Robert C. Allen (Chapel Hill \& London: The University of North Carolina Press), 173.

3 Richard Dyer, White (London \& New York: Routledge), 11-12.

4 John Hartigan Jr., Odd Tribes: Toward a Cultural Analysis of White People (Durham \& London: Duke University Press, 2005$), 1$.

5 Amanda E. Lewis, "What Group?" Studying Whites and Whiteness in the Era of 'Color-Blindness'," Sociological Theory 22, no. 4 (December 2004): 626.

6 Derald Wing Sue, "The Invisible Whiteness of Being: Whiteness, White Supremacy, White Privilege, and Racism," in Addressing Racism: Facilitating Cultural Competence in Mental Health and Educational Settings, eds. Madonna G. Constantine and Derald Wing Sue (Hoboken, NJ: John Wiley \& Sons Inc., 2006), 15-30.

7 Sara Ahmed, "A Phenomenology of Whiteness," Feminist Theory 8, no. 2 (2007): 157.

8 Catrin Lundström, "The White Side of Migration: Reflections on Race, Citizenship and Belonging in Sweden," Nordic Journal of Migration Research 7, no. 2 (2017): 79-87.

9 Thomas K. Nakayama, "Whiteness and Media," Critical Studies in Media Communication 17, no. 3 (2000): 364.

10 Not claiming that all Swedes are white or have been viewed as white in all historical periods.

11 Elsa Peralta and Lars Jensen, "From Austerity to Postcolonial Nostalgia: Crisis and National Identity in Portugal and Denmark," in Austere Histories in European Societies, eds. Stefan Jonsson and Julia Willén (London: Routledge, 2016), 88-105.

12 Tobias Hübinette and Catrin Lundström, "Three Phases of Hegemonic Whiteness: Understanding Racial Temporalities in Sweden," Social Identities 20, no. 6 (2014): 423-437. The authors ascribe whiteness to Sweden's past as the centre of state race biology, the later phase of multiculturalist anti-racism, and the present time characterized by a white melancholia that unites the far-right longing for a homogeneous Sweden and the multiculturalists longing for a Sweden with no far-right mobilization. Interestingly then, Sweden's whiteness unites those ideologically opposed to each other; the racist far right and the colorblind anti-racist multiculturalists.

13 Population Statistics 2020 "Utrikes födda efter län, kommun och födelseland 31 december 2020" [Foreign-born population according to region, municipality, and country of birth $31^{\text {st }}$ of December 2020], https://www.scb.se/hitta-statistik/statistikefter-amne/befolkning/befolkningens-sammansattning/befolkningsstatistik/. 236,975 persons were born in Africa, most of whom in Somalia and Eritrea and 798,328 in Asia, most of whom were born in Syria, Iraq, and Iran. As Sweden does not collect statistics on race, no statistics are available on the number of non-white Swedes. Estimates can only be made based on persons born in non-white countries, yet their Sweden-born children are excluded from the statistics. 
14 Jens Rydgren, From Tax Populism to Ethnic Nationalism: Radical Right-Wing Populism in Sweden (New York \& Oxford: Berghahn Books, 2006), 108.

15 Sweden Democrats, "Sverigedemokraternas migrationspolitiska inriktningsprogram" [Sweden Democrats: Orientation Programme of Migration Politics], https://sd.se/wp-content/uploads/2018/08/Migrationspolitiskt-inriktningsprogram.pdf

16 Diana Mulinari and Anders Neergaard, "The Sweden Democrats, Racisms and the Construction of the Muslim Threat," in Global Islamophobia: Muslims and Moral Panic in the West, eds. George Morgan and Scott Poynting (Farnham: Ashgate, 2012), 67-82.

17 Tobias Hübinette and Malinda Andersson, "Between Colourblindness and Ethnicisation: Transnational Adoptees and Race in a Swedish Context," Adoption \& Fostering 36, no. 3-4 (2012): 99.

18 In July 2021, the Swedish newspaper Dagens Nyheter investigated racism in medical facilities by calling more than 100 facilites with a request to meet a "Swedish Swedish" or "ethnically Swedish" doctor or dentist. Around half of the requests were accommodated, with responses such as "We have two light ones at least. I can sign you up for a Swedish dentist" and "I have Stina who is Swedish. Moa grew up here but is adopted. So if you wish, we can book you for Stina." The investigation illustrates how exclusions that often are masked as language skill-related were actually based on race and how the lack of an explicit language on race and whiteness is expressed in relation to concrete racist actions. (u.a.), "Patienter tillåts välja läkare med enbart svenskt ursprung - över hela landet" [Patients allowed to choose doctor with only Swedish origin - throughout the country], Dagens Nyheter, July 26, 2021, https://www.dn.se/sverige/patienter-tillats-valja-lakare-med-enbart-svensktursprung-over-hela-landet/

19 Tobias Hübinette and Catrin Lundström, "Den svenska vithetens melankoli” [The melancholy of Swedish whiteness], Glänta 2 , no. 19 (2011): 28-35.

20 lbid.

21 Hynek Pallas, Vithet $i$ svensk spelfilm 1989-2010 [Whiteness in Swedish feature film 1989-2010], Doctoral Dissertation, Gothenburg: Filmkonst, 2011

22 Katarina Mattsson and Katarina Pettersson, "Crowning Miss Sweden - National Constructions of White Femininity," NORA—Nordic Journal of Women's Studies 15, no. 4 (2007): 243.

23 Tia Tyree, "African American Stereotypes in Reality Television," Howard Journal of Communications 22, no. 4 (2011): 394-413.

24 Mark C. Hopson, “Now Watch Me Dance': Responding to Critical Observations, Constructions, and Performances of Race on Reality Television," Critical Studies in Media Communication 25, no. 4 (2008): 441-446.

25 Katrina E. Bell-Jordan, "Black. White. and a Survivor of The Real World: Constructions of Race on Reality TV, Critical Studies in Media Communication 25, no. 4 (2008): 353-372.

26 Catherine R. Squires, "The Conundrum of Race and Reality Television," in A Companion to Reality Television, ed. Laurie Ouellette (Chichester: Wiley \& Sons, Inc., 2017), 265.

27 Bell-Jordan, "Black.White. and a Survivor of The Real World."

28 Rachel E. Dubrofsky, The Surveillance of Women on Reality Television: Watching The Bachelor and The Bachelorette (Plymouth: Rowman and Littlefield, 2011).

29 Ibid, 29

30 Rachel E. Dubrofksy, "The Bachelor. Whiteness in the Harem," Critical Studies in Media Communication 23 , no. 1 (2006): 54.

31 See for example Olivia Burke, "Why Are 'The Bachelor' and 'The Bachelorette' Still So White?," The Tempest, November 24, 2019, https://thetempest.co/2019/11/24/entertainment/why-is-the-bachelor-so-white/. Burke notes, "Throughout the years, the franchise has featured many contestants that have come from a wide variety of backgrounds but these contestants typically get much less screen time, with many sent home at an early point of the season, and so are much less likely to be chosen at the end of their season."

32 See for example, Lily Karlin, "All Jokes Aside, 'The Bachelor' Has A Diversity Issue", The Huffington Post, December 6, 2017, https://www.huffpost.com/entry/the-bachelor-diversity-issue_n_6554644 and Emma Gray and Claire Fallon, "The Bachelor' Has a Race - And Racism - Problem," The Huffington Post, October 19, 2020, https://www.huffpost.com/entry/ the-bachelor-race-and-racism_n_5f809b0fc5b6e5c31ffde7c0

33 Eric Deggans, "Dismantling 'The Bachelor's' Racist And Sexist Elements Has Only Just Begun," NPR, June 12, 2020, https:// www.npr.org/2020/06/12/876117467/dismantling-the-bachelors-racist-and-sexist-elements-has-only-justbegun?t=1606900247154

34 Esther Peeren and Irina Souch, "Romance in the Cowshed: Challenging and Reaffirming the Rural Idyll in the Dutch Reality TV Show Farmer Wants a Wife," Journal of Rural Studies 67, (2019): 37-45.

35 Localized versions of Farmer Wants a Wife have appeared in the following countries: Australia, Austria, Belgium (Flanders and Wallonia), Bulgaria, Canada, Croatia, Czech Republic, Denmark, Estonia, Finland, France, Germany, Greece, Hungary, Italy, Lithuania, The Netherlands, Norway, Poland, Portugal, Romania, Serbia, Slovenia, Slovakia, South Africa, Spain, Sweden, Switzerland, Ukraine, and the USA.

36 In the case of farmer Leif, an additional expression of whiteness could also be located in the mere fact that he is an avocado farmer. Whereas the farmers in the Farmer Seeks Wife filmed in Sweden typically have dairy, meat, or egg farms, the Jorden Söker Runt spin-off depicts farmers working with food products less typical in Sweden. Avocado, a word derived from the Aztec language Nahuatl, came to Sweden as late as in the 60s. In recent times, avocado has gained an explosive popularity in the 
West, fuelled not least by white millennials discovering avocado toast and guacamole. Avocado - this recent white obsession has also been named the 'green gold' (a good metaphor for modern-day white colonizers) - to the degree that it has become more profitable for Mexican drug cartels to cultivate avocados than trade drugs.

37 Julia Willing, "'Farmer Wants A Wife' Finally Returned Last Night and Yep, It's Still As White and Straight As You Remember," BuzzFeed, July 27, 2020, https://www.buzzfeed.com/juliawilling/farmer-wants-a-wife-lacks-all-forms-of-diversity

38 Jan Teurlings, "Producing the Ordinary: Institutions, Discourses and Practices in Love Game Shows," Continuum: Journal of Media \& Cultural Studies 15, no. 2 (2001): 253.

39 Jelle Mast, "The Dark Side of Reality TV: Professional Ethics and the Treatment of Reality Show Participants," International Journal of Communication 10 (2016): 2179-2200.

40 Peralta and Jensen, "From Austerity to Postcolonial Nostalgia."

41 Catrin Lundström, "Creating 'International Communities' in Southern Spain: Self-Segregation and 'Institutional Whiteness' in Swedish Lifestyle Migration," European Journal of Cultural Studies 22, no. 5-6 (2009): 799-816.

42 In addition, the Spanish Empire was responsible for the colonization and genocide of numerous Indigenous peoples in the Americas.

43 Alana Lentin and Gavan Titley, The Crises of Multiculturalism (London \& New York: Zed Books, 2011$), 204$.

44 John Urry, The Tourist Gaze (London: SAGE, 1990), 2-3.

45 James Jupp, "Seeking Whiteness: The Recruitment of Nordic Immigrants to Oceania," Scandinavian and European Migration to Australia and New Zealand 13, (1999): 39.

46 For example, the original show, 90 Days Fiancé, follows a number of couples who have applied for or received a K-1 visa (a type of visa available to foreign fiancés of US citizens) and therefore have a period of 90 days to marry in the US and the spin-off 90 Day Fiancé: The Other Way, where the American citizen moves abroad to live with and marry their partner in their own country.

47 Elizabeth D. Matos, "Post-Colonial Portuguese Migration to Mozambique: An Examination of Causes, Effects and Future Implications for Development," International Migration 47, no. 3 (2009): 161.

48 Ibid.

49 Lisa Åkesson, "European Migration to Africa and the Coloniality of Knowledge: The Portuguese in Maputo," Third World Quarterly 42, no. 5 (2021): 922-938.

50 Sayaka Osanami Törngren, Nahikari Irastorza, and Dan Rodríguez-García, "Understanding Multiethnic and Multiracial Experiences Globally: Towards a Conceptual Framework of Mixedness," Journal of Ethnic and Migration Studies 47, no. 4 (2021): 763-781.

51 Homi K. Bhabha, The Location of Culture (London \& New York: Routledge, 1994/2012).

52 The colonial language, Portuguese, is the only official language of Mozambique and is spoken by around $50 \%$ of the population, especially in urban areas. Most Mozambicans speak several languages. Over 40 languages are spoken in Mozambique, among which many are Bantu languages.

53 Note that censor bars were inserted by authors for privacy purposes since the footage includes minors.

54 Isabel Cserno, "Whiteness Studies and the Colonial Aesthetic: Western Popular Culture and the Representations of Race," Ethnic Studies Review 29, no. 2 (2006): 68.

\section{Biographies}

Georgia Aitaki is Lecturer in Media and Communication Studies at Örebro University, Sweden. Her current research focuses on critical approaches to television and popular culture and, specifically, questions of inclusions/exclusions, with an empirical focus on Greek, Swedish, and US media. Her work has appeared in journals such as Media, Culture and Society, Social Semiotics, Screen, and in a number of anthologies.

Nina Carlsson is postdoctoral researcher in Political Science at Södertörn University in Stockholm, Sweden. Her research revolves around questions of national belonging and boundary-making, with a focus on policies on national minorities and immigration in European nation-states. Her previous work has been published in Ethnic and Racial Studies and Journal on Ethnopolitics and Minority Issues in Europe. 